Lepr Rev (1996) 67, 217-221

\title{
Two unusual nerve abscesses-lepromatous leprosy and pure neural leprosy: case reports
}

\author{
G. RAMESH KUMAR, P. V. RAMANA, \\ N. VASUNDHARA \& \\ M. KUMARASWAMY REDDY* \\ Department of Dermatology, S.V. Medical College \& S.V.R.R. \\ Govt. General Hospital, Tirupati-517 507, AP India; \\ *Department of Pathology S.V. Institute of Medical Sciences \\ Tirupati-517 507, AP India
}

Accepted for publication 22 April 1996

Summary We report two cases of nerve abscesses, one suffering from lepromatous leprosy (LL) and the other from tuberculoid neural leprosy. Neither had any signs of reactions. Both were untreated cases. Surgical nerve decompression and systemic prednisolone had resolved the nerve abscess in the first case, whereas the second one responded only to surgical nerve decompression. The unusual nature of clinical presentation of nerve abscess has been outlined.

\section{Introduction}

Nerve abscess in leprosy is commonly seen in paucibacillary leprosy especially during reactions, but has rarely been reported in multibacillary forms. ${ }^{1-4}$ Pure neural leprosy usually presents with thickening of one or more peripheral nerve trunks in association with sensory/motor disturbance or both. ${ }^{5}$ In this report we present two cases, one case of lepromatous leprosy (LL) and one case of pure neural tuberculoid leprosy, both exhibiting some unusual features.

\section{Case reports}

CASE 1

A 25-year-old man presented with a swelling near the right elbow region of 2 months and diff use thickening of facial skin and ears of 2 years duration. Physical examination revealed multiple symmetrical coppery to erythematous papules, nodules and diffuse infiltrations involving the chin, forehead, ears, shoulders and chest. A large fusiform deep-seated nodule of $6 \times 4 \mathrm{~cm}$ was seen on the medial side of right elbow region. The 


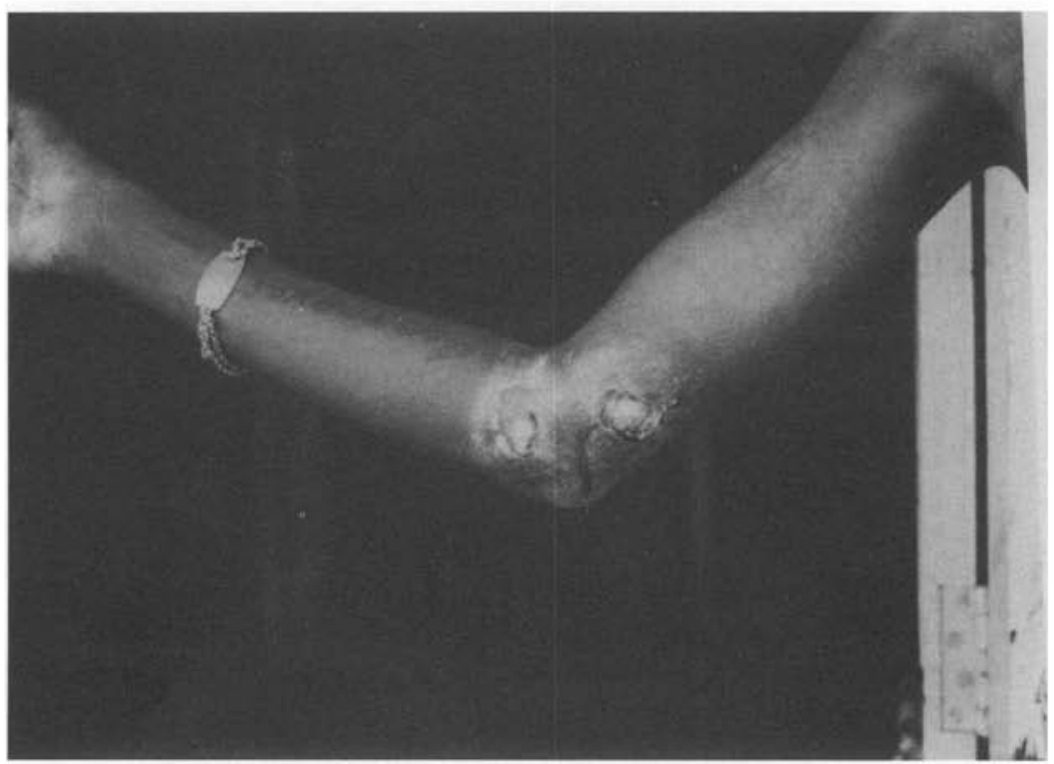

Figure 1. Shows fusiform swelling with discharging sinuses near elbow region.

skin over the mass was stretched, oedematous and adherent to underlying structures. There were multiple sinuses discharging pus (Figure 1). The nodule was very tender, movable from side to side but not vertically and was found to be continuous with the thickened ulnar nerve. The left ulnar nerve also was diffusely thickened. Bilateral and symmetrical thickening of the lateral popliteal, posterior tibial and radial cutaneous nerves was noted. Glove and stocking anaesthesia was noticed. There was no motor deficit or deformity. All other systems were normal. The patient was apyrexial.

A skin smear from an ear nodule and a pus smear from the sinus showed a MI of 20 percent and 0 percent, respectively. BI was $6+$ (Ridley's logarithmic scale) from both the sites. The cytology of pus revealed necrotic material admixed with few neutrophils. The lepromin test was negative. Skin biopsy of a cutaneous nodule confirmed the diagnosis of LL. All other investigations were normal. The patient was put on multidrug therapy as recommended by WHO and oral prednisolone $(40 \mathrm{mg})$ after surgical nerve decompression. The mass subsided and the sinuses healed in 1.5 months time. Steroids were continued for another 1.5 months in a tapering dose and stopped.

\section{CASE 2}

A 20-year-old man sought our advice for small swellings over his right upper limb. He denied any history of hypopigmented patches on the body or antileprosy drug therapy, but reported frequent attacks of pain and paraesthesia of the same limb. Clinical examination revealed $8-10$ firm, mildly tender subcutaneous nodules $(0 \cdot 5-5 \mathrm{~cm})$ distributed over the medial and lateral sides of the arm, medial and dorsolateral sides of the elbow and dorsolateral side of the forearm on the right side (Figure 2). The skin over the 


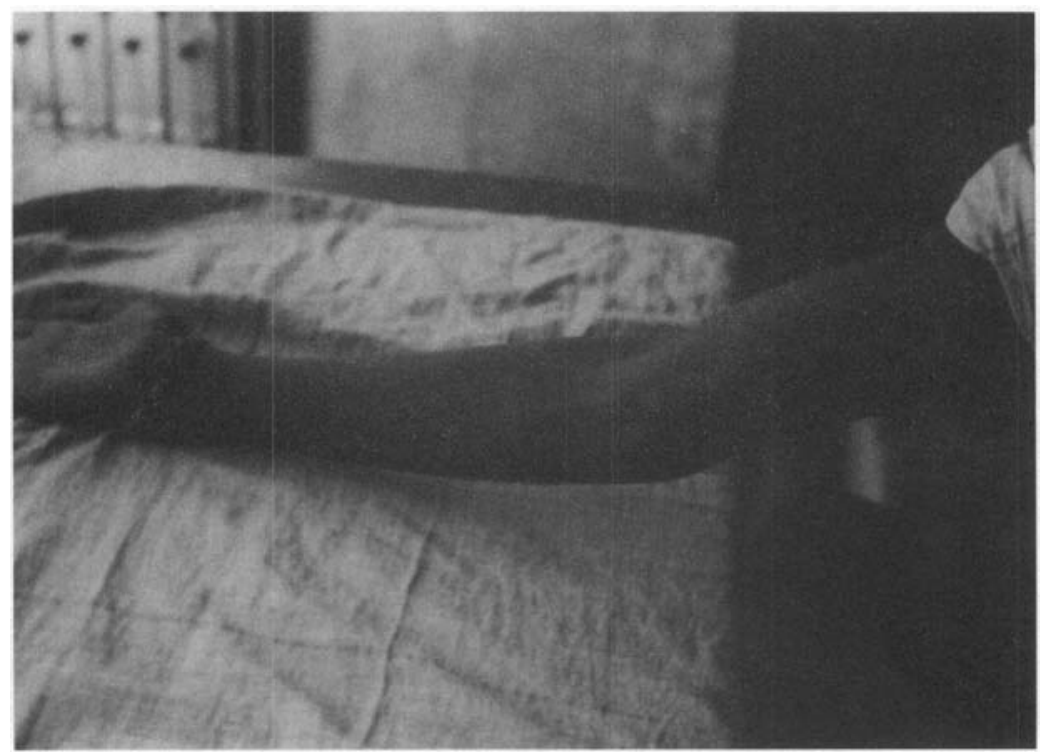

Figure 2. Shows subcutaneous nodules and beaded cutaneous nerves of forearm.

nodules was normal and free from underlying structures. Thick cord-like cutaneous nerves of the arm and forearm could be felt above and below the nodules. Patchy hypoaesthesia of the arm and forearm skin was noticed, but there were no hypopigmented patches anywhere on the body. The main peripheral nerve trunks were normal. Surgical exploration revealed a shiny fusiform nodule with glistening cords above and below. Manipulation of the cords elicited paraesthesia. The nodule was incised. Thick yellow pus was drained. Cytology of the pus showed caseating material, a few epitheloid cells and lymphocytes.

Pus and skin smears (from right forearm and ears) were negative for AFB. The lepromin test was strongly positive (3+). Nerve biopsy confirmed the diagnosis of neural tuberculoid leprosy (Figure 3(a) and (b)). The patient was put on MDT according to the WHO recommendations. The nerve abscesses required surgical nerve decompression as they failed to respond to oral prednisolone.

\section{Discussion}

In the earlier reports typical manifestations of Type 2 lepra reaction were present in most of the LL patients who developed nerve abscesses. ${ }^{1-4,6}$ The unusual feature of LL in our case is the occurrence of nerve abscess in the absence of other evidence of Type 2 lepra reaction.

A cold abscess of nerve appears to be rare, and its presence in pure neural leprosy indicates that it may be TT or BT. In such cases a lepromin test helps. ${ }^{5}$ The peculiar features of neural tuberculoid leprosy in the present case are: 1, the involvement of 

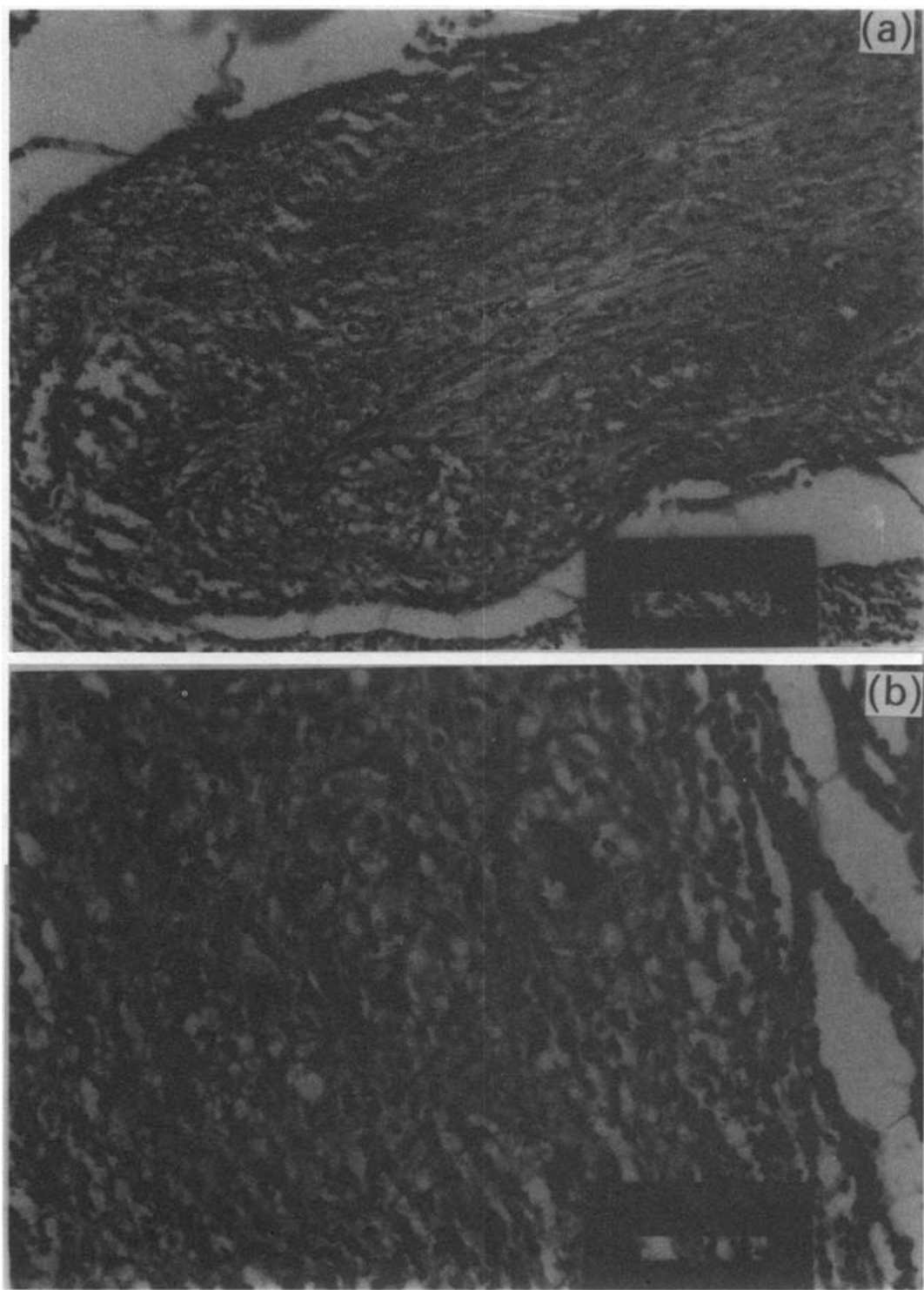

Figure 3. Histological features of biopsied nerve specimen. (a) Shows epitheloid granuloma consisting of epitheloid cells and lymphocytes involving the nerve $(\mathrm{H} \& \mathrm{E} 10 \times 20)$; (b) Magnified view of the granuloma showing epitheloid cells, lymphocytes and Langhan giant cells $(\mathrm{H} \& \mathrm{E} 10 \times 40)$.

cutaneous nerves alone in the form of subcutaneous nodules and headed cord-like structures, but without thickening of the peripheral nerve trunks; and 2, the appearance of multiple nerve abscesses as mildly tender subcutaneous nodules without any clinical evidence of Type 1 lepra reaction. In the present case these may be multiple cold abscesses. Multiple nerve abscesses are said to be more common in $\mathrm{LL}^{1-3}$ than in tuberculoid leprosy. ${ }^{4}$ 


\section{Acknowledgments}

We would like to thank Dr B. Srinivas, Senior Resident, Department of Pathology, Sri Venkateswara Institute of Medical Sciences, Tirupati for taking photographs and Mr. M. Venkata Ramana Reddy, Programme Assistant, Department of Pathology, Sri Venkateswara Institute of Medical Sciences, Tirupati for keying the manuscript.

\section{References}

1 Job CK, Bhaktaviziam C. Nerve abscess in lepromatous leprosy. A report of a patient. Lepr Rev, 1967; 38: $243-247$.

2 Enna CD, Brand PW. Peripheral nerve abscess in leprosy. Report of three cases encountered in dimorphous and lepromatous leprosy. Lepr Rev, 1970; 41: 175-180.

3 Roy Choudary RSB, Srinivas H. Nerve abscess in lepromatous leprosy. A case report and discussion of Pathogenesis. Lepr India, 1979; 49: 330-38.

4 Siddalingaswami MK, Rao KS. Nerve abscess in leprosy: a retrospective study. Lepr Rev, 1993; 64: 35-61.

5 Jopling WH, McDougall A C (eds). Handbook of Leprosy (4th edition) London: Heinemann Medical Books, 1988. pp. 38-85.

6 Malaviya GN, Lavania RK, Mukher jee A, Ramu G. Nerve abscess in lepromatous leprosy. Lepr India, 1982; 54: $123-29$. 